\title{
Improving the technical and environmental performance of piston engines by upgrading the fuel system
}

\author{
N. S. Kochev ${ }^{1}$, B. P. Zhilkin ${ }^{1}$ and $L$. V. Plotnikov ${ }^{1, *}$ \\ ${ }^{1}$ Ural Federal University named after the first President of Russia B.N. Yeltsin, Ekaterinburg, Russia
}

\begin{abstract}
The article presents the results of an experimental study of the dispersion of superheated water through cylindrical channels and nozzles of piston internal combustion engines under different initial conditions. The advantages and disadvantages of modern diesel engine fuel systems are discussed in the article. The process of explosive boiling in relation to the fuel system of a piston engine is formulated and briefly described. A description of the laboratory setup and methods of conducting experiments is given in the article. The results of the visualization of sprayed superheated water through a cylindrical channel and through a diesel engine nozzle of 21/21 dimension are presented. The original scheme of the fuel system for a diesel engine using the effect of explosive boiling is proposed. Preliminary estimates have shown that the use of such a fuel system will increase the reliability of the combustion chamber elements of a piston engine, reduce specific fuel consumption (up to $2 \%$ ) and reduce the amount of harmful substances in exhaust gases (an average of $12 \%$ compared with traditional fuel systems).
\end{abstract}

\section{Introduction}

Today, piston internal combustion engines (ICE) are widely used in all sectors of the economy. Therefore, improving the technical and environmental performance of piston ICEs is one of the urgent tasks in the field of engine building $[1,2]$.

Manufacturers of piston engines are in constant search of ways of reduction of emission of harmful substances due to tougher environmental regulations for exhaust gases. Scientists and engineers suggest improving the environmental performance of piston ICE through the use of fuels with various additives [3, 4], improvement of fuel equipment [5-8], fine-tuning of the combustion chamber designs and channels in the cylinder head $[9,10]$, as well as the use of different filters in the exhaust system [11].

In particular, this problem is solved by the modernization of fuel systems, which makes them more complex and loaded. Increasing the pressure of fuel injection allows to produce finer atomization of the fuel in the combustion chamber, which leads to its more complete combustion, but requires high quality of manufacturing of parts of fuel systems; all this increases the cost of the engine. Moreover, the loss of engine power to the high-pressure fuel pump drive is increased and also the reliability of the system as a whole is reduced. In turn, the use of Common Rail fuel systems with electronic control partly solves environmental and economic problems, but it requires the use of complex diesel engine control units, and also involves the use of many sensors and solenoid valves. Traditional fuel systems in the form of a block fuel injection pump and hydraulically-controlled injectors have a simpler design compared to Common Rail. The advantages of such a system are low cost and high reliability. The disadvantage is the limitation on the maximum injection pressure and, consequently, the limitation on fuel efficiency and environmental friendliness.

This article presents the results of the development of the original fuel system based on the effect of explosive boiling. This system makes it possible to produce a thin spray of fuel (diameter of drops 1-3 microns) and at the same time it is more reliable, due to the lack of a highpressure fuel pump.

\section{Description of the experimental setup}

The phenomenon of explosive boiling is based on the process of a sharp phase transition of the liquid - steam $[12,13]$. Any liquid can act as a working medium, depending on the tasks to be solved. The effect of explosive boiling is widely used in various fields of technology. The article [14] presents the results of experimental studies and mathematical simulation of the characteristics of evaporation of superheated water jets to increase the efficiency of desalination for sparsely populated islands and remote areas. Original technologies for the use of superheated liquid sprays in technological installations for the food industry are proposed in article [15]. The article [16] presents the results of physical and numerical simulation of superheated fuel spray in jet engines for aircraft.

In our case, it is necessary to effectively spray fuel in the combustion chamber of the diesel engine, i.e. to obtain the most homogeneous mixture of air and fuel. In

\footnotetext{
* Corresponding author: plotnikovlv@ mail.ru
} 
order to realize explosive boiling, the heating of the fuel to a temperature close to thermodynamically critical is carried out before it is fed to the nozzle. The fuel is heated under conditions of a constant volume up to a temperature above the critical one for the heaviest fraction contained in the fuel, but below the decomposition temperature of the lightest fraction; at the same time, pressure rises above critical. Such heating leads to the fact that boiling occurs when fuel enters the combustion chamber; this causes an efficient atomization of the fuel and creates an even distribution of droplets throughout the entire volume of the combustion chamber.

The design scheme of the working chamber of the experimental setup is shown in Figure 1; it provides a steady flow of liquid for several tens of seconds.

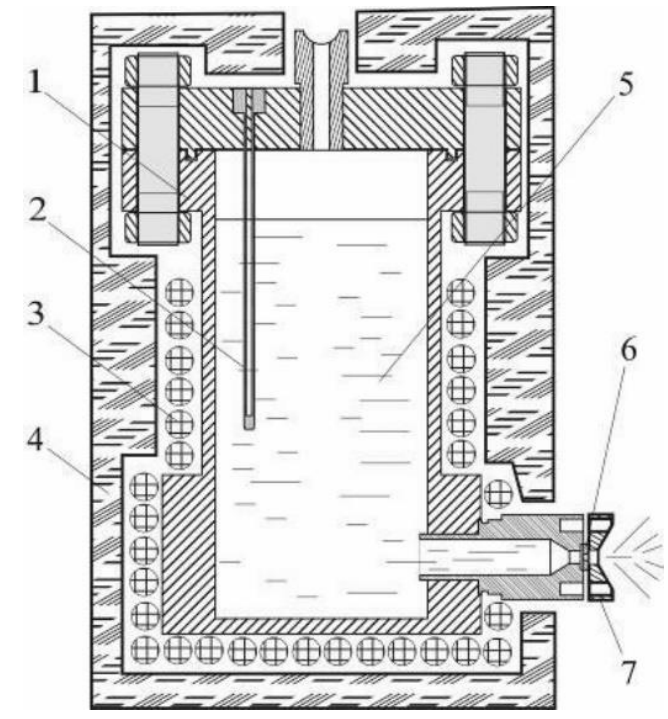

Fig. 1. Scheme of the working chamber of the experimental setup: 1 - body of the working chamber; 2 - thermocouple housing; 3 - heating element; 4 - heat insulator; 5 - liquid; 6 channel; 7 - clamping flange.

The initial states of the liquid in the working chamber varied along the saturation line or along the isobars and covered a wide range of parameters, including the conditions of explosive boiling. A more detailed description of the experimental setup and the methodology for conducting experiments is presented in [17]. In this study, the working fluid was water.

The spray nozzle with a cylindrical channel and its main dimensions are shown in Figure 2.

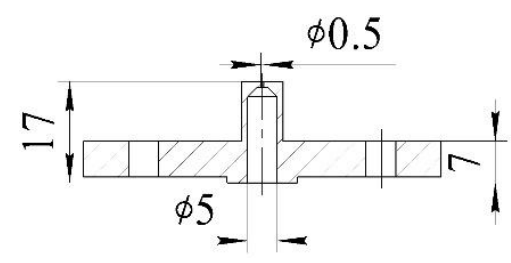

Fig. 2. Spray nozzle with cylindrical channel.

In this case, the length of the spray hole in the nozzle was $l \approx 0.7 \mathrm{~mm}$, the diameter of the cylindrical channel was $d=0.5 \mathrm{~mm}$.

\section{The results of experimental studies}

The shapes of water jets when flowing through a nozzle with a cylindrical channel from the saturation line for different values of temperature in the high-pressure vessel $\mathrm{T}_{0 \mathrm{~s}}$ are shown in Figure 3.

It is shown that the jet boils beyond the exit section of the channel at a certain distance in the direction of the flow; there is some delay in boiling (Figure 3,a). The number of activated boiling centers increases with an increase in the degree of overheating of the water and the boiling point approaches the exit section of the channel; the jet acquires the form shown in Figure $3, b$ at temperature $T_{0 s}=180{ }^{\circ} \mathrm{C}$. The flow is fairly homogeneous, with smooth external boundaries near the channel. It should be noted that fine dispersion is provided when water flows in the temperature range $T_{0 s}$ from $220^{\circ} \mathrm{C}$ to $250{ }^{\circ} \mathrm{C}$. The boiling up occurs already inside the channel at a temperature $T_{0 s}=300{ }^{\circ} \mathrm{C}$ and a two-phase flow with irregular boundaries is observed at the outlet (Figure 3,c).

Thus, the increase in the temperature of the liquid before the spraying hole gradually reduces the diameter of the droplets at the outlet and increases the uniformity of their distribution along the flow; moreover, this trend is observed only in a certain temperature range. In this case, the mixing process is improved by more uniform mixing of the fuel with the air mixture in the combustion chamber.

The results of the experiments indicate that it is possible to significantly change the shape of the jet by operatively controlling the degree of overheating of the liquid and the geometrical parameters of the spray hole of the nozzle, and thus it is possible to create such a configuration that best matches the shape of the engine combustion chamber and would be optimal for this mode
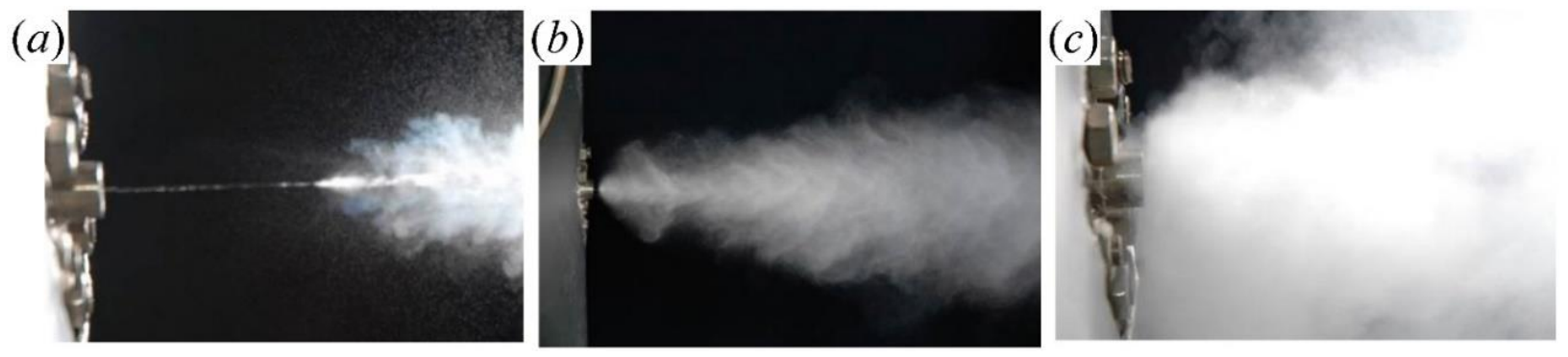

Fig. 3. Types of water jets at the expiration of the saturation line: a) $\left.\left.T_{0 s}=170{ }^{\circ} \mathrm{C} ; b\right) T_{0 s}=182{ }^{\circ} \mathrm{C} ; c\right) T_{0 s}=300{ }^{\circ} \mathrm{C}$. 
piston ICE operation. As a result, with regard to piston engines, these measures should lead to an increase in the engine power, a decrease in specific fuel consumption, a decrease in the toxicity of exhaust gases and an increase in the reliability of the structural elements of the combustion chamber.

Studies for a real diesel engine injector were carried out after obtaining positive results on the spray of superheated water from a nozzle with one channel. The diesel injector (produced by "Volgodizelapparat") was installed in the experimental setup described above. The channel diameter in the diesel injector was $0.35 \mathrm{~mm}$, the number of channels (spray holes) was 8 , and the camber angle was $145^{\circ}$. The initial parameters in the working chamber was varied from water temperature of $21^{\circ} \mathrm{C}$ and the pressure in the working chamber of $\mathrm{P}_{0 \mathrm{~S}}=1.2$ $\mathrm{MPa}$ (unsaturated state) to the parameters of the saturation line of water at the temperature of $250{ }^{\circ} \mathrm{C}$ and a pressure of $\mathrm{P}_{0 \mathrm{~S}}=4.0 \mathrm{MPa}$. The results of the experiments are presented in Fiure. 4. It is shown that boiling occurs at the activated heterogeneous centres near the outlet section of the channel when the liquid is sprayed at the saturation line parameters; this leads to a gradual expansion of the jet in the direction of flow.
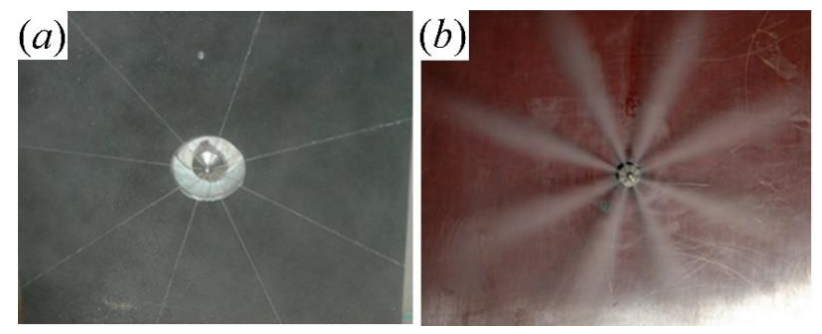

Fig. 4. Forms of water jets from a diesel engine nozzle with different initial parameters: a) initial temperature of $21 \mathrm{C}$ and pressure of $1.2 \mathrm{MPa}$; b) initial temperature $\mathrm{TC}=250^{\circ} \mathrm{C}$ and pressure 4.0 MPa.

It should be noted that depending on the degree of overheating, changes in the jet shape of the sprayed liquid occurred similarly to the results of the liquid flow through one channel. In particular, the overheating of the liquid contributed to a decrease in the diameter of the water droplets at the outlet and increased the uniformity of their distribution along the flow; while the opening angle of the jet torch was increased. Reducing the size of droplets and controlling the jet shape has a positive effect on engine power, fuel consumption, exhaust gas toxicity and reliability of the main parts and assemblies.

Thus, the presented experimental data indicate the possibility of a more efficient atomization of the fuel, that is, an almost instantaneous transition to the gas phase due to the effect of explosive boiling.

\section{Piston engine fuel system using the effect of explosive boiling}

To implement the considered method of fuel supply using the effect of explosive boiling, the original scheme of the fuel system for diesel was developed, which is shown in Figure 5.
The new system works as follows. The fuel from the tank (8) passes through the coarse fuel filter (13) and then the fueling pump pumps it into the boilers to heat the fuel (10); before that, it passes through the fuel fine filter (12). Positions (8), (13), (11) and (12) form the low-pressure fuel circuit. Heaters are installed in boilers (10), by means of which the fuel is heated to the required temperature (sensor control). Further, the overlap of the electromagnetic valves (14) and (15) occurs so that only one of the boilers is connected to the fuel rail (9) and at the same time isolated from the low-pressure fuel circuit. The fuel rail (9) accumulates the overheated fuel in the boiler (10) and smoothest pressure pulsations. The fuel pressure sensor (4) and the pressure limiter (5) are mounted in the body of the ramp, which serve to maintain the required parameters of the fuel before injection. The fuel rail cavity is connected to the piezoelectric injectors (6) by means of high-pressure pipelines, which serve to supply superheated fuel to the engine cylinders. The injectors are controlled by the engine control unit (1) through an electrical signal and the injector amplifier (2).

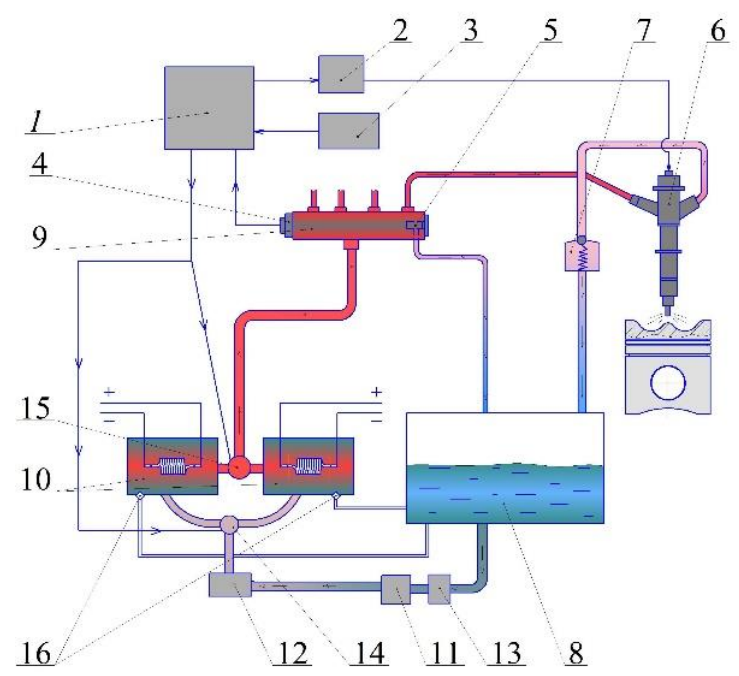

Fig. 5. Scheme of diesel fuel system using the effect of explosive boiling: 1 - engine control unit; 2 - injector booster; 3 - sensors; 4 - fuel pressure sensor in the ramp; 5 - pressure limiter; 6 - piezoelectric nozzle; 7 - check valve; 8 - fuel tank; 9 - fuel rail; 10 - boiler for heating the fuel; 11 - fuel pump; 12 - fuel fine filter; 13 - coarse fuel filter; 14 - solenoid valve switch fuel line low pressure; 15 - solenoid valve switch fuel line high pressure; 16 - residual pressure relief valve.

This scheme is just one of the possible ways to implement the fuel injection system using the effect of explosive boiling. For example, the heat of the engine exhaust manifolds can be used instead of heaters.

\section{Conclusions}

Thus, the following main conclusions can be made on the basis of the data obtained.

The results of the investigation of the explosive boiling process in relation to the fuel system of a diesel engine were presented; the results of superheated water spray through a cylindrical channel and through a nozzle 
of a real diesel engine were shown; the original scheme of the diesel fuel system using the effect of explosive boiling was developed.

The implementation of the developed fuel system in piston engines can lead to the following positive effects: 1) power increase (up to 5-10\% due to the absence of power losses on the drive of the high-pressure fuel pump); 2) improving the reliability of the elements of the combustion chamber and the engine as a whole (improving the reliability indicator by $3-5 \%$ due to the reduction of thermal stresses and the number of friction pairs); 3) reduction of specific fuel consumption (up to $2 \%$ due to an increase in the completeness of fuel combustion); 4) reduction in the amount of harmful substances in exhaust gases by $10-15 \%$ (according to preliminary estimates, this is higher than the level of modern diesel engines with the Common Rail system and the use of exhaust filtration systems).

All the above proves the possibility of solving actual problems of modern engine-building in the field of ecology, reliability and fuel efficiency when using the proposed fuel system based on the explosive boiling effect. It should be noted that the new fuel system for piston engines requires additional computational and experimental studies with other liquids (including diesel fuel) and more thorough engineering study for subsequent implementation in industry.

\section{References}

[1] J.B. Heywood, Internal combustion engine fundamentals (New York: McGraw-Hill) 458 (1988)

[2] V.N. Lukanin, K.A. Morozov, Internal combustion engines (Moscow: Mechanical Engineering) 368 (1995)

[3] J. Hwang, D. Qi, Y. Jung, C. Bae, Renewable Energy 63, 9-17 (2014)

[4] Ch. Zhang, A. Zhou, Y. Shen, Y. Li, Q. Shi, Applied thermal engineering 127, 312-318 (2017)

[5] H. Xu, B. Yin, S. Liu, H. Jia, Brazilian society mechanical sciences and engineering 39(10), 3757-3767 (2017)

[6] R.Z. Kavtaradze, D.O. Onishchenko, I.A. Zinoviev, A.S. Golosov, Proceedings Rus. Academy Sciences. Energy 5, 152-159 (2016)

[7] N.S. Malastowski, Ph.B. Barchenko, L.V. Grekhov, A.S. Kuleshov, Int. J. Applied Engineering Research 11(23), 11189-11198 (2016)

[8] V.A. Markov, M.A. Saveliev, Truck 9, 3-7

[9] R.Z. Kavtaradze, D.O. Onishchenko, A.S. Golosov, A.V. Shibanov, Alternative fuel transport 5(53), 31-39 (2016)

[10] R.Z. Kavtaradze, A.A. Zelentsov, Bulletin

MGTU N. E. Bauman. Engineering 6(105), 59-73 (2015)

[11] H. Zhong, J. Tan, Y. Wang, J. Tian, N. Hu, J. Cheng, X. Zhang, Energy \& Fuels 31(9), 9833-9839 (2017)

[12] K.V. Lukynov, A.A. Starostin, P.V. Skripov, Int. J. Heat Mass Transfer 106, 657-665 (2017)
[13] A.V. Reshetnikov, N.A. Mazheiko, V.N. Skokov, V.P. Koverda, Int. J. Heat Mass Transfer 85, 965-970 (2015)

[14] S. Mutair, Y. Ikegami, Desalination 251(1-3), 103-111 (2010)

[15] I. Sotome, Y. Ogasawara, Y. Nadachi, M. Takenaka, H. Okadome, S. Isobe, Jap. J. Food Engineering 10(3), 163-173 (2009)

[16] J. Lee, R. Madabhushi, C. Fotache, S. Gopalakrishnan, D. Schmidt, Proceedings Combustion Institute 32(II), 3215-3222 (2009)

[17] B.P. Zhilkin, L.V. Plotnikov, N.S. Kochev, A.V. Reshetnikov, N.A. Mazheiko, K.A. Busov, High Temperature 57(3), 1-5 (2019) 